\title{
Análise das manifestações patológicas da ponte sobre o Rio Pedra no município de Delmiro Gouveia/AL: estudo de caso
}

Nas estruturas de obras de arte especiais de concreto armado (ex.: pontes e viadutos) a avaliação periódica das patologias possui grande importância visto a necessidade de manter um nível de segurança estrutural conforme as normativas vigentes, evitando assim a ruína e aumentando a proteção a vida como também a conservação do patrimônio. Contudo no Brasil, não é comum a realização de manutenção periódica nas pontes, consequentemente, manifestações são frequentemente observadas. Em alagoas, atualmente diversas estruturas não se enquadram dentro dos parâmetros exigidos em normas, oferecendo possíveis riscos aos seus usuários e ao meio. Diante disso, o presente trabalho analisa de forma visual e por meio de ensaios in loco as patologias presentes em alguns dos componentes estruturais da ponte sobre o Rio Pedra do município de Delmiro Gouveia/AL, baseadas nas normas vigentes: NBR 6118 (2014), NBR 7584 (2012), NBR 14178 (2001), NBR 15575 (2013), Norma DNIT/090 (2006), Norma DNIT/122(2009), Manual de inspeção rodoviária DNIT/709 (2004) e LNEC E391 (2019). Com base nos resultados (2012), NBR 14178 (2001), NBR 15575 (2013), Norma DNIT/090 (2006), Norma DNIT/122(2009), Manual de inspeção rodoviária DNIT/709 (2004) e LNEC E391 (2019). Com base nos resultados das análises, nota-se que a estrutura contém diversos locais onde há o comprometimento das armaduras devido a oxidação, além de carbonatação, existência de aberturas, focos de ataque resistência entre os pilares mais e menosresistentes como também houve diferenças de resistência no valor de $16,19 \%$ entre faces de um mesmo pilar. De posse dos métodos construtivos atuais no âmbito da engenharia civil, a ponte analisada compreende um estado preocupante de estabilidade estrutural o que necessita de estudos mais profundos em que é possível traçar planos de manutenções corretiva e periódicas com o intuito de garantir a segurança quanto ao uso e revitalizar estruturalmente a obra.

Palavras-chave: Manifestações Patológicas; Pontes; Concreto Armado; Manutenção.

\section{Analysis of the pathological manifestations of the bridge over the Pedra River in the municipality of Delmiro Gouveia/AL: case study}

\begin{abstract}
In structures of special reinforced concrete works of art (eg bridges and viaducts) the periodic assessment of pathologies is of great importance, given the need to maintain a level of structura safety in accordance with current regulations, thus avoiding ruin and increasing protection against life as well as heritage conservation. However, in Brazil, it is not common to perform periodic maintenance on the bridges, consequently, the manifestations are frequently observed. In Alagoas, currently several structures do not fit within the standards required by standards, offering potential risks to their users and the environment. Therefore, the present work analyzes visually and by means of in loco tests the pathologies present in some of the structura components of the bridge over the Pedra River of Delmiro Gouveia/AL, based on the current norms: NBR 6118 (2014), NBR 7584 (2012), NBR 14178 (2001), NBR 15575 (2013), Standard DNIT/090(2006), Standard DNIT/122 (2009), Road Inspection Manual DNIT/709 (2004) and LNEC E391 (2019). Based on the results of the analysis, it is noted that the structure contain several places where there is the compromise of the reinforcement due to oxidation, as well as carbonation, openings, efflorescence attack foci, infiltration, clogging of the drainage system among others. Through the sclerometry test, it was possible to verify that there was areduction of about $23.3 \%$ of the resistance between the more and less resistant columns, as wellas $16.19 \%$ resistance differences between faces of the same pillar. With current construction methods in the field of civil engineering, an analyzed bridge comprises a state concerned with structural stability or the use of deeper studies in which it is possible to draw up corrective and periodic maintenance plans in order to ensure safety in use and structurally revitalize the work.

Keywords: Pathological Manifestations; Bridges; Reinforced Concrete; Maintenance.
\end{abstract}

Topic: Engenharia Civil

Reviewed anonymously in the process of blind peer.
Received: 15/10/2019

Approved: $21 / 01 / 2020$
Rafael Alves da Silva (iD

Universidade Federal de Alagoas, Brasil http://lattes.cnpq.br/0585892266626577

http://orcid.org/0000-0002-7821-4178

rafael.eng.alves2@gmail.com

Erik Eduardo Honorio Pereira (iD

Universidade Federal de Alagoas, Brasil

http://lattes.cnpq.br/3552772815213959

http://orcid.org/0000-0003-4468-163X

erik99ed@gmail.com

Rogério de Jesus Santos (iD

Universidade Federal de Alagoas, Brasil

http://lattes.cnpq.br/2787941849604621

http://orcid.org/0000-0001-7714-3059

rogerio.santos@delmiro.ufal.br
Referencing this:

SILVA, R. A.; PEREIRA, E. E. H.; SANTOS, R. J.. Análise das manifestações patológicas da ponte sobre o Rio Pedra no município de Delmiro Gouveia/AL: estudo de caso. Inventionis, v.2, n.1, p.1-14, 2020. DOI: http://doi.org/10.6008/CBPC2674-6395.2020.001.0001 


\section{INTRODUÇÃO}

Com o crescente desenvolvimento da construção civil e sua importância socioeconômica para o país, torna-se necessário discutir um de seus principais problemas: as manifestações patológicas nas estruturas de concreto armado. $O$ estudo dessas manifestações é a principal ferramenta para evitar a deterioração precoce e o colapso das estruturas. As manifestações patológicas podem ser originadas em todas as etapas de uma construção, desde a fase de projeto como também ao longo de sua vida útil.

De modo geral segundo a NBR-6118 (2014) todas as obras de concreto devem apresentar uma boa durabilidade, de forma que conservem a sua estabilidade, segurança e aptidão durante sua vida útil. Roque et al. (2005) destacam, que quando se almeja qualidade na construção é preciso conhecer o material utilizado e seu comportamento, afinal nenhum material é imensuravelmente durável. Entender sua estrutura e como esse material se comporta no meio ambiente é imprescindível para que a construção atenda os critérios de qualidade esperados, evitando assim sua degradação prematura.

Qualidade, tempo e economia são parâmetros primordiais quando empregados na construção, contudo ao se prezar a economia acima da qualidade e segurança muitos dos empreendimentos são propensos a apresentar falhas desde sua concepção. Dorea et al. (2010), observa que as tentativas de ocultar falhas e lesões durante todo processo de execução da obra por boa parte dos profissionais envolvidos, com o intuito de evitar prejuízo financeiro, podem acarretar detrimentos graves em questão de tempo. Segundo Souza et al. (1998) o estudo das patologias implica em novos aprendizados e abordagens de estruturas a serem construídas ou reformadas, aliado aos aspectos econômicos, sociais e ambientais, torna-se mais efetivo a concepção e revitalização de obras.

No contexto geral dos estudos da patologia estrutural no Brasil, ainda não é dado a relevância ideal para a prevenção, cuidado e tratamento dos sinistros ocorridos nas construções que pode ser devido ao desconhecimento dos métodos e ensaios para identificação das patologias e possíveis tratamento. Entre os normativos vigentes sobre inspeção de obras de arte espaciais no Brasil, a mais recente é o da Associação Brasileira de Normas Técnicas (ABNT) a norma, ABNT 9452:2019. Essa norma descreve os tipos de inspeções e suas especificidades, tais como, cadastral, rotineira, especial e extraordinária. Em razão disso, o presente trabalho tem o propósito de investigar as anomalias e sinistros da ponte sobre o rio da Pedra localizada na avenida Caxangá no município de Delmiro Gouveia/AL.

\section{METODOLOGIA}

A metodologia seguiu os procedimentos apresentados por Dorea et al. (2010), embasado pela norma de projeto de estruturas de concreto NBR 6118 (2014), pela norma de desempenho de estruturas NBR 15575 (2013), pelas orientações do ensaio E391 do LNEC (2019) e pelo manual de inspeção de pontes rodoviárias IPR 709 (2004) fornecido pelo DNIT.

A ponte estudada localiza-se no município de Delmiro Gouveia/Alagoas, situada na avenida Caxangá, sendo um ponto obrigatório de passagem para o município que faz ligação direta com cinco cidades (Paulo 
Afonso, Pariconha, Água Branca, Canindé e Piranhas). De acordo com dados da prefeitura local, a ponte em estudo tem 4,20 metros de altura a partir da superfície mais profunda do nível do rio; possui cerca de 16.5 metros de comprimento e 8,75 metros de largura. No estudo da ponte foi analisado cada elemento estrutural de forma individual, sendo definidos de acordo com a Figura 1.

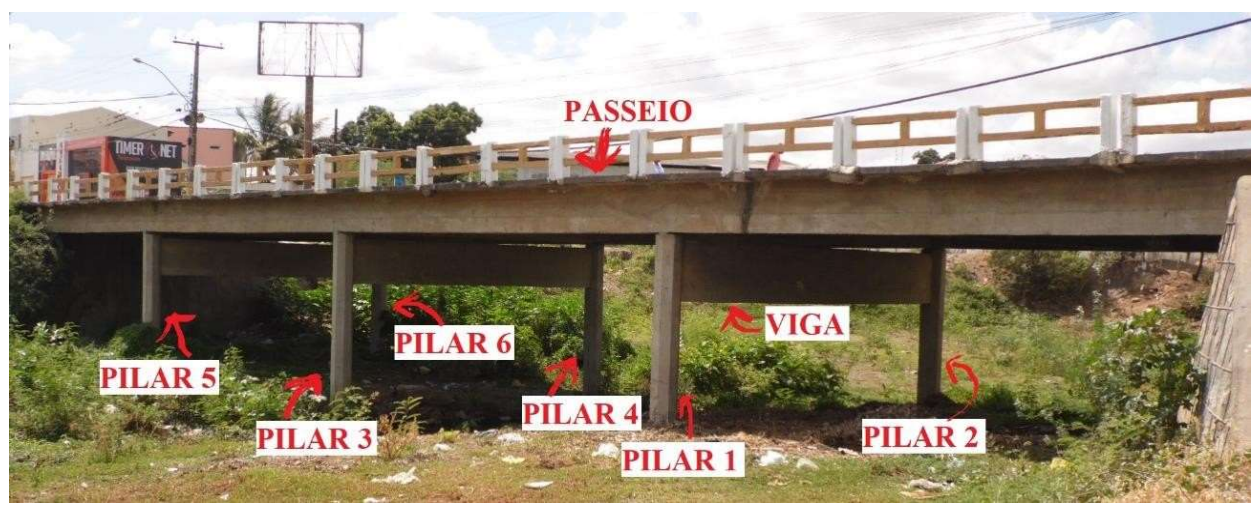

Figura 1: Divisão estrutural das análises.

\section{Etapas metodológicas}

Baseado na metodologia de Dorea et al. (2010), após a escolha do objeto de estudo, os procedimentos metodológicos foram estruturados pelos seguintes passos: Investigação e aquisição de informações sobre a ponte fornecidos pela prefeitura de Delmiro Gouveia e pelo Departamento de Estradas de Rodagem - DER; Realização de visitas in loco com objetivo de obter um relatório fotográfico do estado da ponte; Aplicação de ensaios usando equipamentos, como: esclerômetro, fissurômetro e solução de fenolftaleína para auxiliar no diagnóstico além de ensaios visuais; Análise dos resultados dos ensaios realizados; Compilação e quantificação dos resultados.

\section{Ensaio de esclerometria}

O ensaio de esclerometria é fundamentado pela norma NBR 7584 (2012) intitulada de Concreto Endurecido - Avaliação da dureza superficial pelo esclerômetro de reflexão - Método de ensaio em que define o ensaio como não destrutivo tendo o objetivo de medir a dureza superficial do concreto. Inicialmente é feito a calibração do esclerômetro com 10 impactos na bigorna de aço (mínimo exigido por norma), visto que a cada 300 golpes com o instrumento faz-se necessário a calibração. O resultado da calibração obedeceu ao índice de correlação apresentado pela equação 1 .

$$
k=\frac{n \cdot I_{E n o m}}{\sum_{i}^{n}=1 I_{E i}}
$$

\section{(Equação 1)}

Sendo:

k: coeficiente de correlação do índice esclerométrico; n: número de golpes na bigorna de aço; $I E_{\text {nom }}$ : índice nominal esclerométrico do aparelho fornecido pelo fabricante; $I_{E i}$ : índice obtido por cada golpe na bigorna de aço.

Ao escolher a superfície de ensaio, foi utilizado o processo de lixamento da superfície com o disco de carbono através de movimentos circulares. Após o lixamento, os moldes de impactos foram realizados seguindo as especificações da norma NBR 7584 (2014), conforme mostra a Figura 2. 


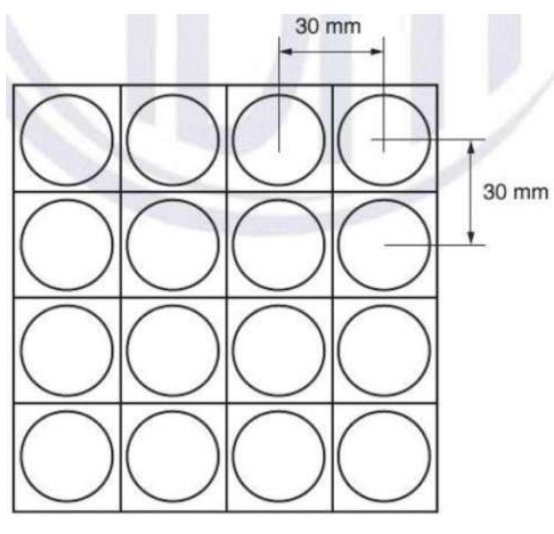

16 impactos

Figura 2: Área de ensaio e pontos de impacto. Fonte: ABNT NBR 7584, 2012.

Os moldes de impacto foram feitos na superfície com material de gesso, para não causar modificações consideráveis nos resultados. Os locais onde visivelmente haviam indícios de patologias foram evitados devido à possibilidade de imperfeições superficiais que podem provocar alterações nos resultados. O processo de aplicação dos impactos com o esclerômetro seguiu os procedimentos de Thomaz (2007).

\section{Ensaio de aberturas}

Para realização do ensaio, foi feito o uso do instrumento fissurômetro, para coletar dados e pressupor as causas patológicas do concreto, como também o grau de degradação. A caracterização das fissuras seguiu a classificação mostrada no quadro 1 mostrando a baixo. Também foram utilizados uma câmera de 13 megapixels, régua milimetrada e lupa.

Quadro 1: Classificação das fissuras de acordo com o tamanho da abertura.

\begin{tabular}{|l|l|}
\hline Tipos de aberturas & Tamanho \\
\hline Fissura & Até $0,5 \mathrm{~mm}$ \\
\hline Trinca & Entre $0,5 \mathrm{~mm}$ a $1,0 \mathrm{~mm}$ \\
\hline Rachadura & Entre 1,0 a $1,5 \mathrm{~mm}$ \\
\hline Fenda & Acima de $1,5 \mathrm{~mm}$ \\
\hline
\end{tabular}

Fonte: IBAPE (2003).

O ensaio de aberturas seguiu os procedimentos da norma NBR 15575 (2013). Foram feitas análises em 6 pilares, no passeio e no tabuleiro da ponte. A escolha dos pontos seguiu o grau de importância destacado no manual de inspeção de pontes do DNIT (2004).

\section{Determinação da profundidade de carbonatação}

O ensaio da profundidade de carbonatação seguiu a metodologia e as especificações do ensaio E391 (2019) do Laboratório Nacional de Engenharia Civil (LNEC), onde foram usados um borrifador e uma solução alcoólica de fenolftaleína, este último mostrando na Figura 3, e um pincel de hastes macias. O ensaio seguiu os procedimentos do LNEC (2019), onde foram analisados pontos divididos em duas categorias: Gravidade I (críticos): pontos que visualmente apresentavam desgaste, armaduras expostas, desagregação, furos ou aberturas em até 1 centímetro de profundidade; Gravidade II (graves): pontos que não apresentam visualmente desgaste abrasivo, porém apresentam aberturas em estruturas de alta importância estrutural 
como pilares, vigas e lajes.

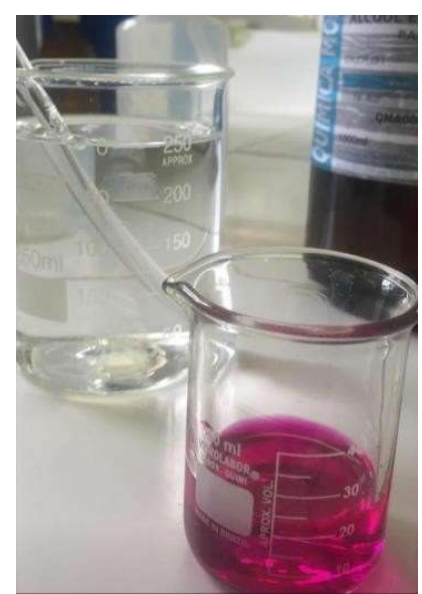

Figura 3: Solução de fenolftaleína.

A análise ocorreu pela observação da reação da solução de fenolftaleína na área de aplicação do concreto. A área correspondente à coloração rosa ilustrada na Figura 3 equivale a área não afetada pela carbonatação, de outro modo, caso a área não apresente coloração roseada esta é classificada como atingida por ação da carbonatação. Previamente, foi feita a limpeza das aberturas com o pincel com haste macia para retirar as impurezas existentes e, logo após, foi feita a aplicação da solução da fenolftaleína e a verificação visual da reação química.

\section{RESULTADOS}

Foi feito a verificação do estado estrutural e das manifestações patológicas existentes, como também foi realizado uma composição de fotos para relatório fotográfico, conforme mostra a Figura 4. Ao analisar visualmente a ponte, mostrado na Figura 4, foi constatado que há indícios de patologia por todo o corpo estrutural.

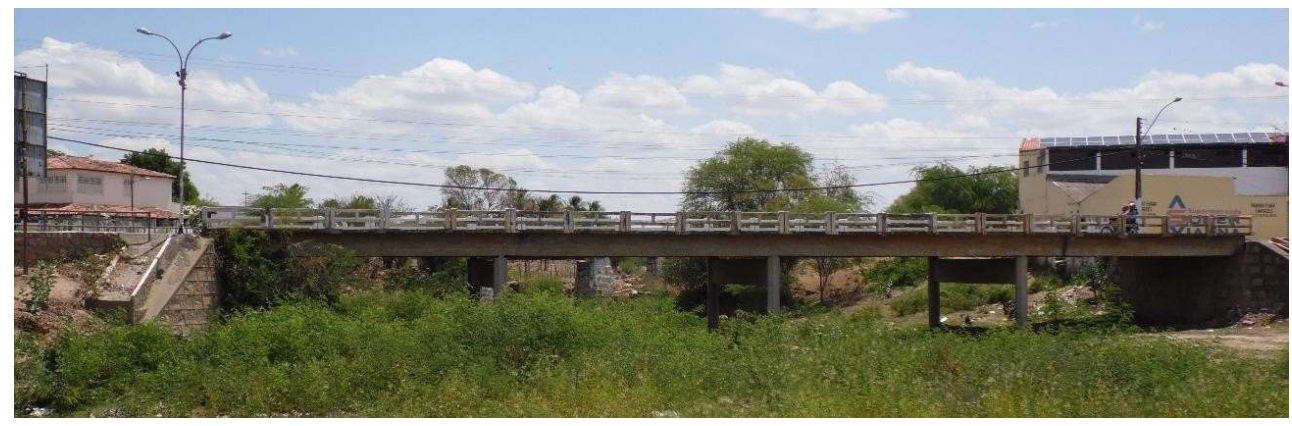

Figura 4: Ponte sobre Rio da Pedra.

\section{Resultado da análise visual}

$\mathrm{Na}$ parte inferior do tabuleiro da ponte encontra-se a exposição de armaduras, que pode ter acontecido por insuficiência no cobrimento ou devido à presença de sais presentes no rio que passa abaixo, conforme as figuras 5-7. 


\section{Armaduras expostas}

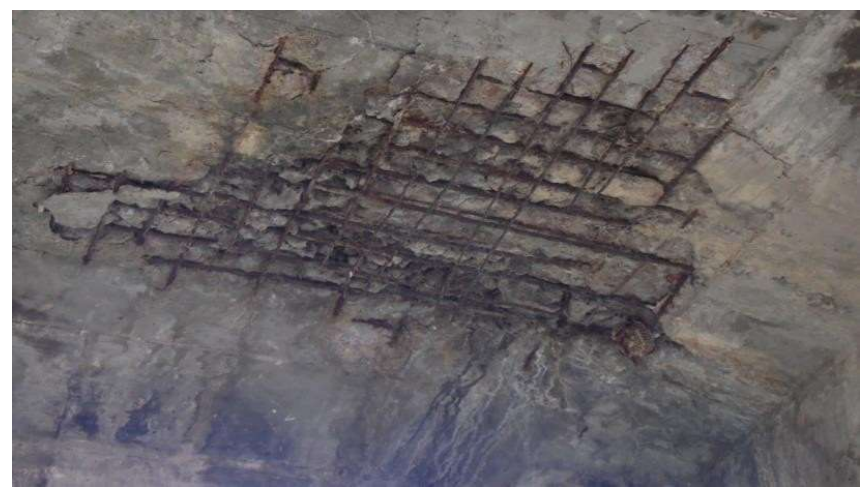

Figura 5: Armadura exposta abaixo do tabuleiro.

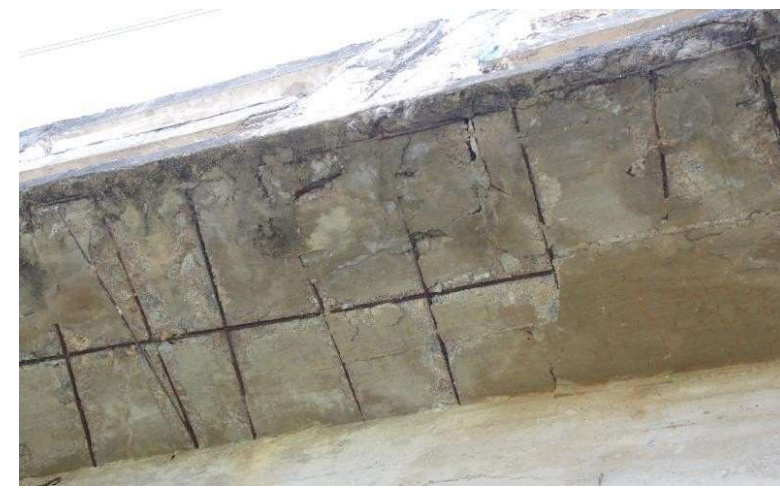

Figura 6: Armadura exposta abaixo do passeio.

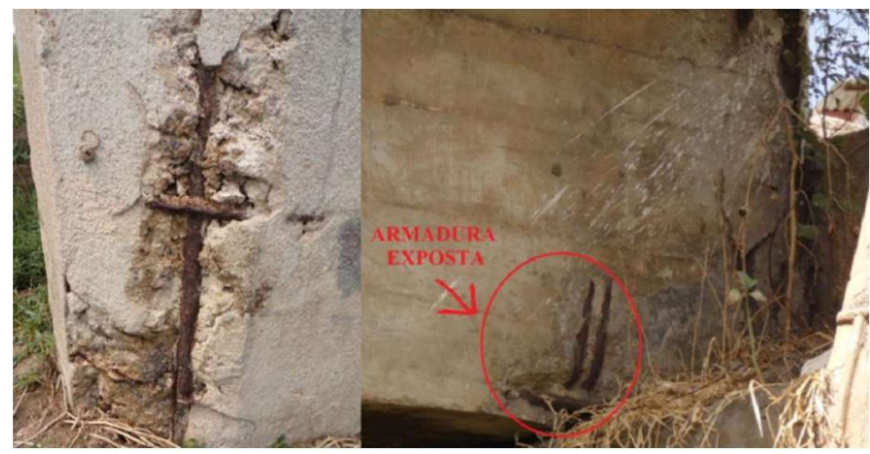

Figura 7: Armadura exposta na base do pilar 2 e no apoio da ponte.

\section{Análise de aberturas}

Foram verificadas aberturas nos pilares, passeio e das junções da ponte. Por se tratar de um importante elemento de transmissão de carga foi analisada a abertura na extensão do elemento como mostra a Figura 8. De acordo com o IBAPE (2003), a abertura mostrada na Figura 8 se caracteriza como fissura (até $5 \mathrm{~mm}$ ). Nas junções da ponte foi observada aberturas de grande gravidade como mostra as Figuras 9 e 11.

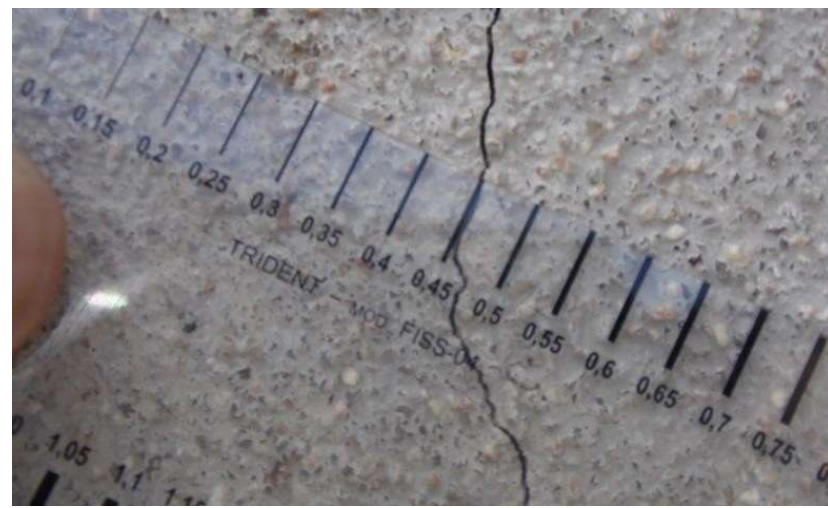

Figura 8: Abertura no pilar 4.

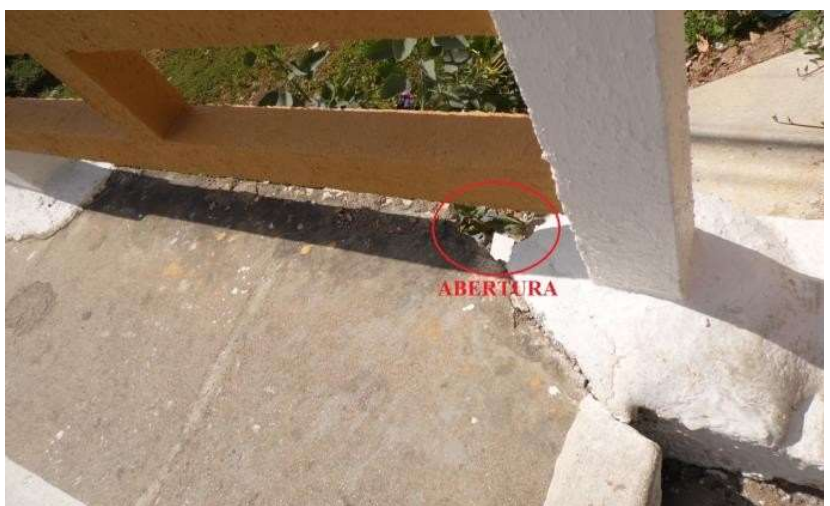

Figura 9: Aberturas no início do passeio.

A abertura mostrada na Figura 9 tem aproximadamente $22 \times 13 \mathrm{~cm}$ de proporções, de acordo com o Quadro 1 desse estudo a abertura é classificada como fenda. De acordo com o DNIT (2004) elementos protendidos com aberturas de fissuras maiores que $0,2 \mathrm{~mm}$, na maioria das situações, indicam sobrecargas expressivas ou deficiência nos esforços de protensão. Foi verificado que nas junções iniciais e finais da ponte existem aberturas de altas proporções, conforme mostra a Figura 10. 


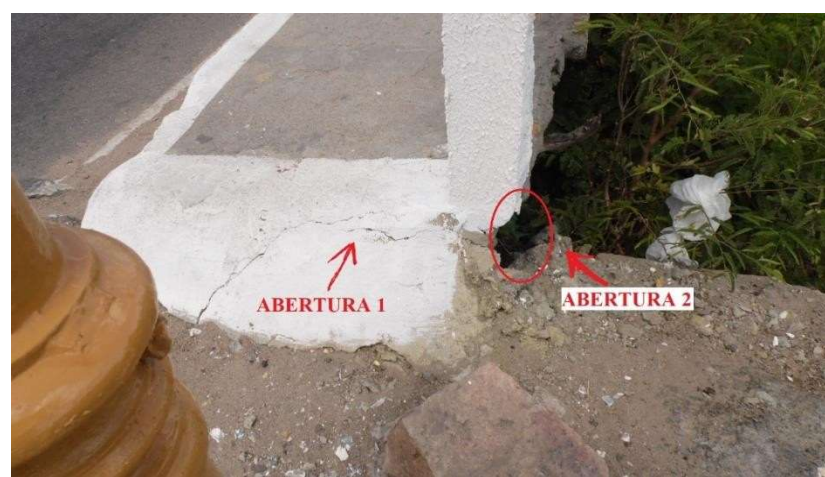

Figura 10: Aberturas no final do passeio.

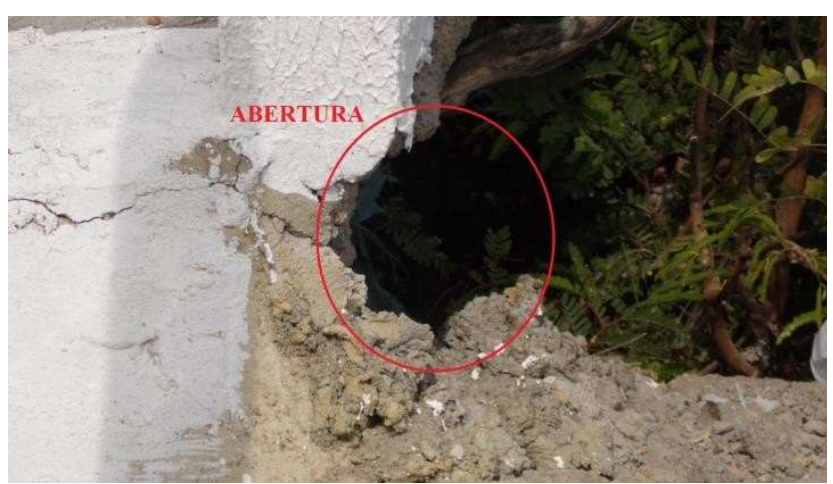

Figura 11: Abertura entre o apoio da ponte e o passeio.

A abertura 1 é encontrada na junção da calçada do passeio e a estrada obteve uma abertura no valor de 0,5 milímetros que, de acordo com o Quadro 1, é classificado como fissura. Já a abertura 2 se encontra na junção do apoio da ponte com o passeio, esta é mais crítica que a primeira visto sua proporção visual, conforme mostra a Figura 11.

As medidas encontradas da abertura foram aproximadamente $17 \times 15$ centímetros, de acordo com Souza et al. (1998) o surgimento de trincas e aberturas podem ser observadas em situações como recalque natural da fundação, sobrecargas exageradas, assim como ações variáveis. Na extensão do passeio foram encontradas várias aberturas e furos existentes conforme mostra as Figuras 12 e 13 que podem ser resultantes de desgaste por uso ou abrasão.

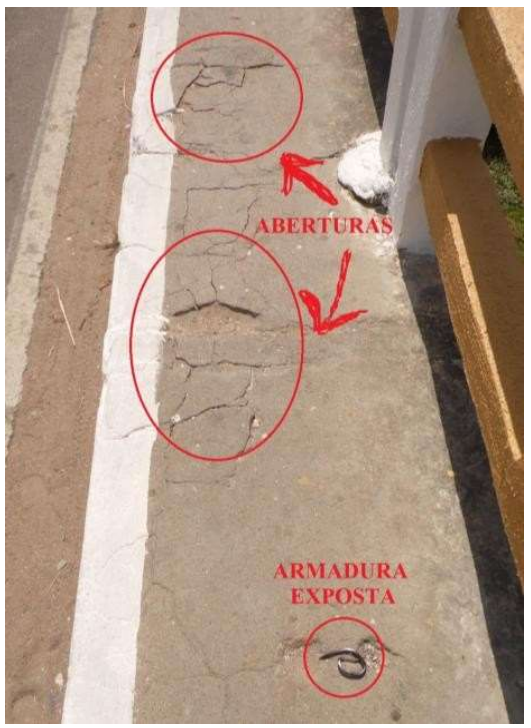

Figura 12: Aberturas no passeio.

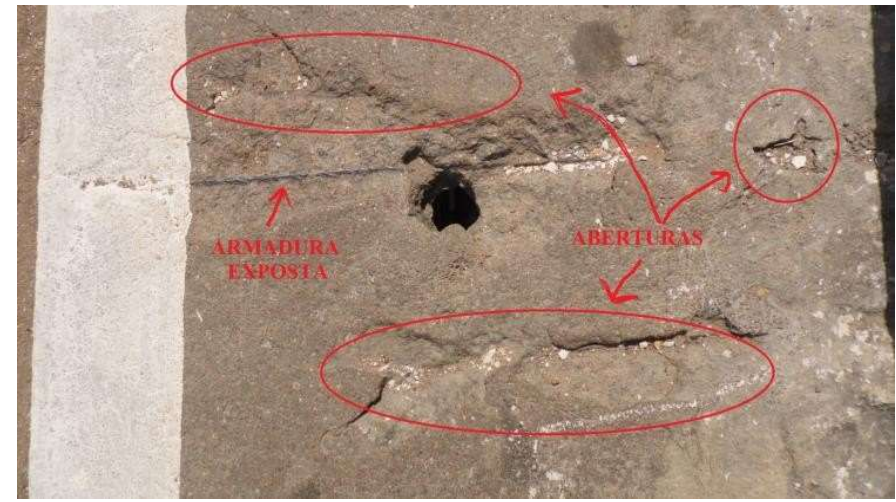

Figura 13: Furo encontrado na parte central do passeio.

Segundo o DNIT (2009), em relação a gravidade das trincas e fissuras para a segurança e durabilidade da estrutura, é possível determinar identificar causas prováveis dos sinistros, contudo se faz necessária a realização de ensaios e análises para identificar todo o conjunto de ações patológicas. Conforme mostra a Figura 13, o furo obteve o diâmetro de 7 centímetros de extensão, sua profundidade não foi medida, porém pode-se ver o rio passando por baixo da ponte por meio do mesmo. Percebe-se o desgaste do passeio representado, além do furo, por diversas aberturas e por armaduras expostas evidenciando a gravidade do estado da ponte. 


\section{Desnível}

Foram encontrados desnível na base do guarda corpo do passeio e nas juntas de dilatação entre a ponte e a estrada conforme mostra as Figuras 14, 15 e 16. Os desníveis não foram medidos devido à falta de acesso a equipamentos de segurança e por logística relacionado à passagem de automóveis e pedestres ininterruptos. Como ilustra a Figura 14, o desnível do guarda corpo se acentua na parte central do vão em que este pode estar diretamente relacionado com a patologia de armadura exposta, apresentada anteriormente.

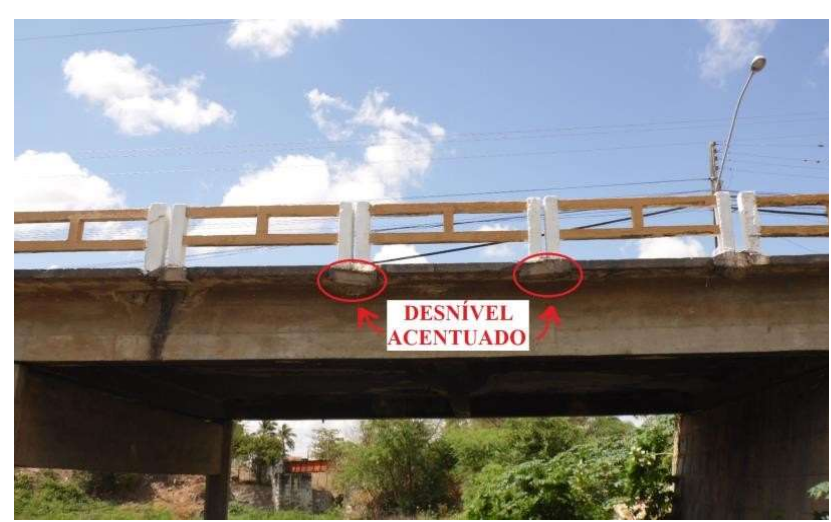

Figura 14: Desnível na base do guarda corpo.

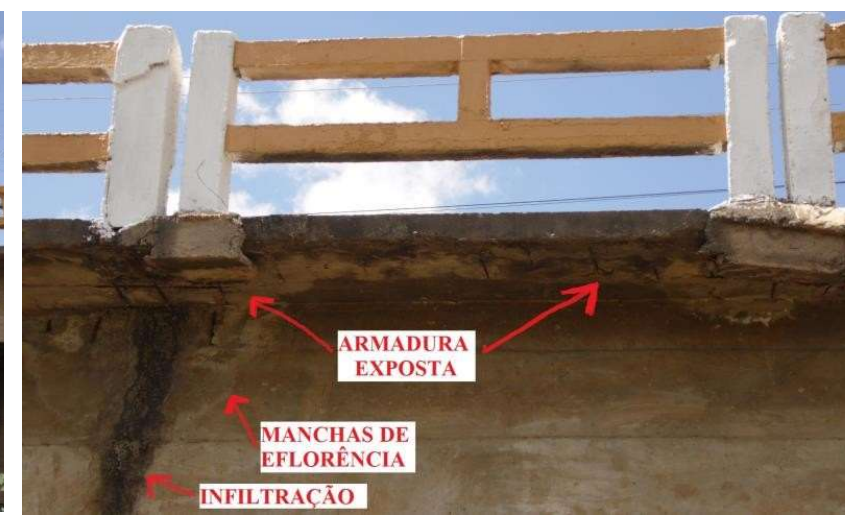

Figura 15: Situação do guarda corpo.

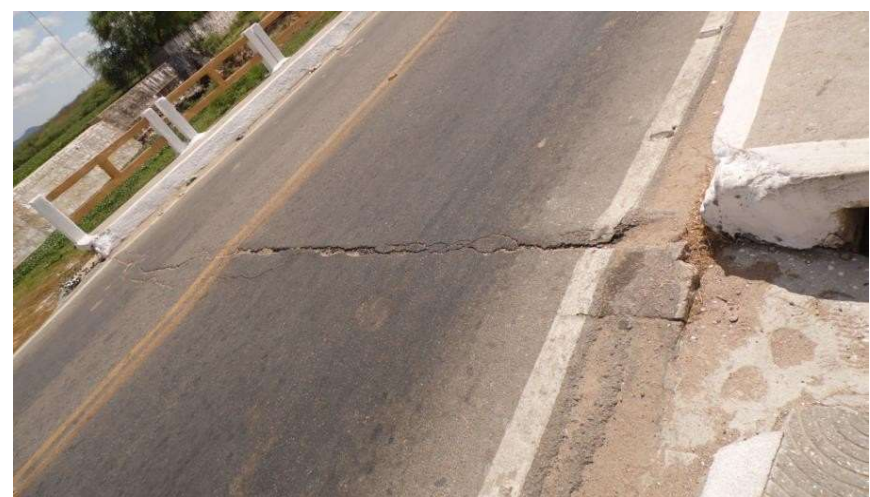

Figura 16: Juntas de dilatação entre a ponte e a estrada.

A altura do guarda corpo mede 15 centímetros a partir da base do passeio. Segundo a norma NBR 14718 (2001), a altura mínima de guarda corpo, considerado com piso acabado, deve ser de 1,10 metros, dessa forma o guarda corpo existente da obra está irregular visto que está fora dos parâmetros de segurança das normas atuais.

O visível desgaste mostrado na Figura 16 ocorre na extensão da largura entre os apoios da ponte o que pode significar a deterioração do material das juntas. Segundo DNIT (2004), ao identificar danos nas juntas deve ser verificado o comportamento do tráfego e dos detritos do meio que podem provocar avarias na estrutura.

\section{Eflorescência e sistema de drenagem}

Foi observada uma grande quantidade de manchas e formas cristalizadas de eflorescências na parte inferior do tabuleiro, conforme mostra a Figura 17. A maioria dos focos de eflorescência estão nas quinas e 
arestas entre lajes, vigas e pilares.

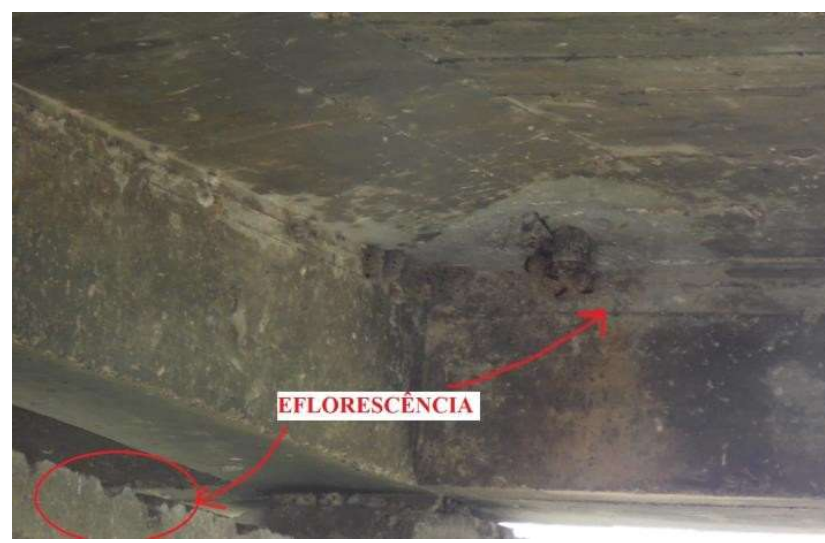

Figura 17: Eflorescência presente em vigas, pilares e lajes.

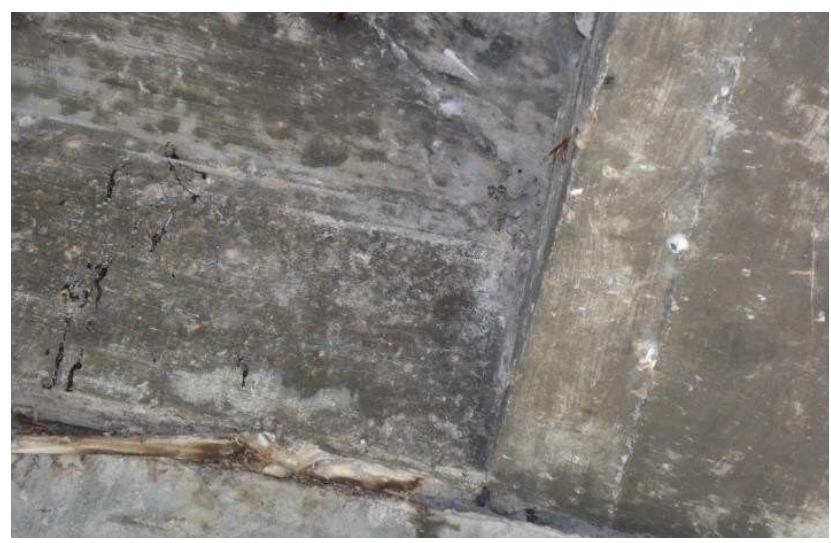

Figura 18: Eflorescência existente na parte inferior do tabuleiro.

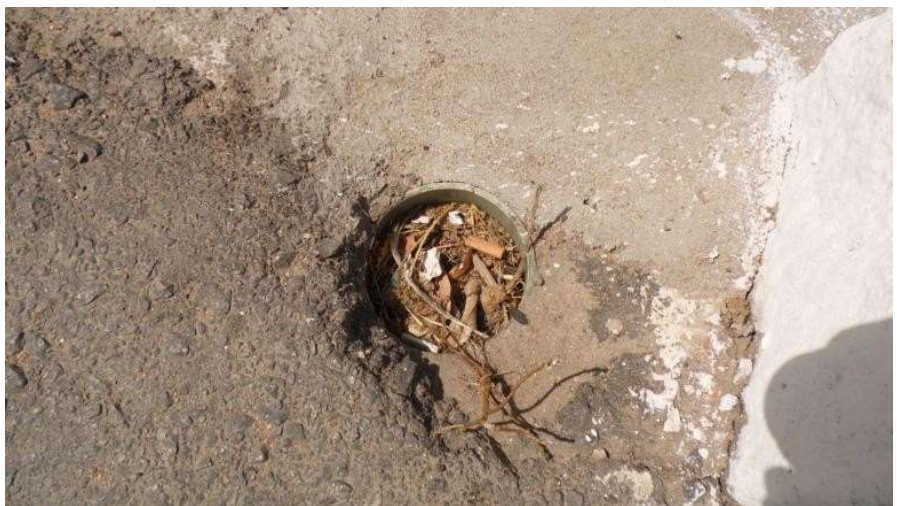

Figura 19: Entupimento do sistema de drenagem da ponte.

Também são encontrados focos em locais onde se tem armaduras expostas e próximas ao sistema de drenagem da ponte. Em algumas situações, todo o corpo estrutural está com indícios de eflorescência, conforme mostra a Figura 18. O sistema de drenagem encontra-se entupido por falta de manutenção preventiva e por talvez corretiva (caso seja necessário). O mesmo não possui ralos para contenção de sujeiras e insetos. Tal entupimento pode causar infiltrações e por conseguintes danos a estrutura, conforme mostra a figura 19.

\section{Ensaio de esclerometria}

Esse ensaio foi feito sob as normativas da NBR 7584 (2012), em que foram analisados os 6 pilares da ponte e a viga central de sustentação do tabuleiro. Como não se obteve acesso ao projeto estrutural da ponte, esse ensaio é de cunho quantitativo visto que não se tem os valores das resistências iniciais do concreto. Os moldes de impacto foram feitos com giz disposto de 16 quadrados, conforme mostra a Figura 20.

Segundo a norma NBR 7584 (2012), elementos estruturais com grandes extensões ou com grandes volumes de concreto devem ser analisados em, pelo menos, duas áreas de ensaio com preferência em faces opostas. Nos pilares 1 e 2 assim como os pilares 5 e 6 somente foi possível analisar uma face do pilar em razão das irregularidades na superfície do concreto e pela dificuldade de acesso do terreno em razão da presença de plantas no local. A Figura 18 ilustra a aplicação do esclerômetro no elemento estrutural. 


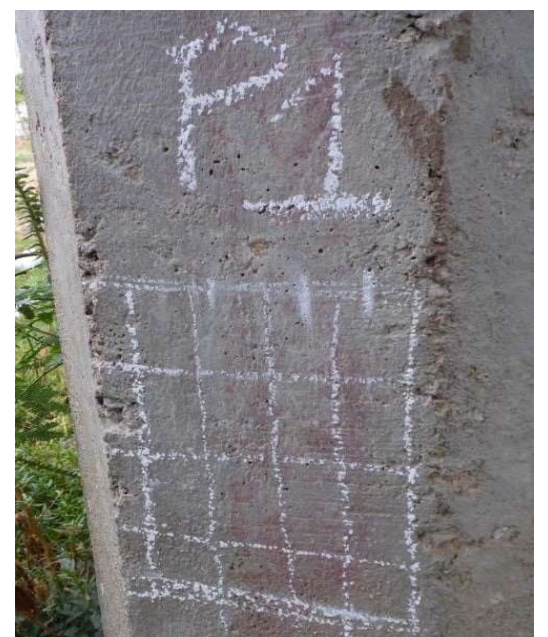

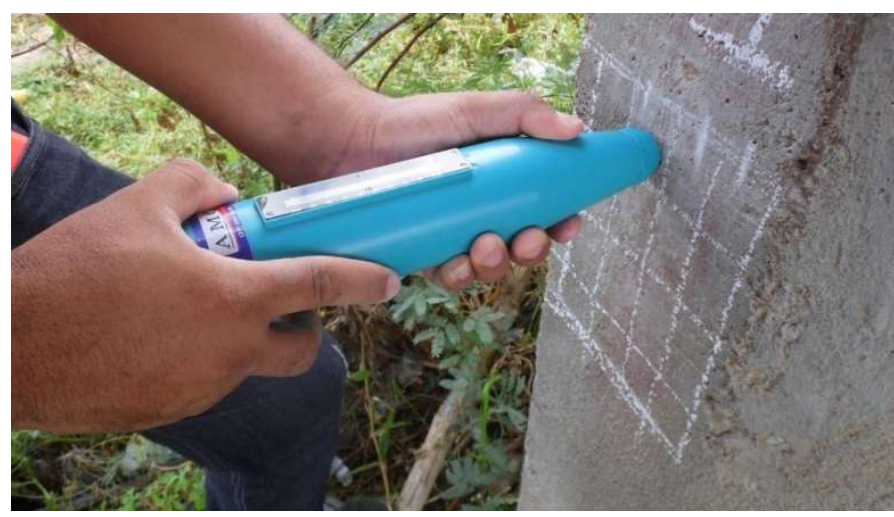

Figura 21: Aplicação dos golpes do esclerômetro no Pilar.

Figura 20: Molde dos impactos do Pilar 1.

Após o processo de lixamento, foi feito o ensaio na superfície com 16 golpes em cada molde, conforme mostra Figura 21. Em posse do valor do fator de correção, agora pode-se calcular corretamente os índices esclerométricos in loco. Seguindo as recomendações da norma NBR 7584 (2012) e realizando o ensaio nas áreas acessíveis, o Quadro 2 dispõe dos resultados do ensaio.

Quadro 2: Resultados do ensaio de esclerometria.

\begin{tabular}{|c|c|c|c|c|c|c|c|c|c|}
\hline \multirow[t]{2}{*}{ PILAR/ÁREA } & \multirow[t]{2}{*}{$\mathrm{P} 1$} & \multirow[t]{2}{*}{$\mathrm{P} 2$} & \multicolumn{2}{|l|}{ P3 } & \multicolumn{2}{|l|}{ P4 } & \multirow[t]{2}{*}{ P5 } & \multirow[t]{2}{*}{ P6 } & \multirow[t]{2}{*}{ V1 } \\
\hline & & & F1 & $F 2$ & F1 & $F 2$ & & & \\
\hline 1 & 43 & 32 & 42 & 41 & 37 & 40 & 42 & 40 & 45 \\
\hline 2 & 39 & 38 & 45 & 44 & 42 & 40 & 44 & 42 & 43 \\
\hline 3 & 38 & 40 & 43 & 46 & 42 & 37 & 46 & 46 & 42 \\
\hline 4 & 32 & 32 & 38 & 39 & 45 & 43 & 49 & 44 & 40 \\
\hline 5 & 44 & 38 & 43 & 44 & 49 & 41 & 43 & 44 & 38 \\
\hline 6 & 42 & 32 & 42 & 39 & 39 & 48 & 44 & 39 & 32 \\
\hline 7 & 40 & 40 & 39 & 46 & 44 & 42 & 42 & 38 & 42 \\
\hline 8 & 41 & 39 & 41 & 42 & 38 & 43 & 58 & 46 & 40 \\
\hline 9 & 50 & 36 & 36 & 32 & 39 & 40 & 41 & 46 & 44 \\
\hline 10 & 42 & 36 & 42 & 46 & 45 & 47 & 42 & 48 & 49 \\
\hline 11 & 42 & 39 & 47 & 45 & 41 & 44 & 44 & 49 & 39 \\
\hline 12 & 32 & 38 & 49 & 42 & 49 & 45 & 46 & 52 & 38 \\
\hline 13 & 49 & 32 & 38 & 42 & 45 & 39 & 49 & 37 & 42 \\
\hline 14 & 43 & 33 & 43 & 44 & 42 & 43 & 39 & 42 & 44 \\
\hline 15 & 38 & 34 & 38 & 45 & 45 & 45 & 44 & 45 & 37 \\
\hline 16 & 40 & 37 & 40 & 45 & 38 & 44 & 46 & 45 & 39 \\
\hline MÉDIA I & 41 & 36 & 42 & 43 & 43 & 43 & 45 & 44 & 41 \\
\hline 10\% MÉDIA & 4,1 & 3,6 & 4,2 & 4,3 & 4,3 & 4,3 & 4,5 & 4,4 & 4,1 \\
\hline$>10 \%$ & 45,1 & 39,6 & 46,2 & 47,3 & 47,3 & 47,3 & 49,5 & 48,4 & 45,1 \\
\hline$<10 \%$ & 36,9 & 32,4 & 37,8 & 38,7 & 38,7 & 38,7 & 40,5 & 39,6 & 36,9 \\
\hline MÉDIA II & 41 & 36,8 & 41,1 & 44 & 40 & 40 & 42 & 45 & 41 \\
\hline k & 1,01 & 1,01 & 1,01 & 1,01 & 1,01 & 1,01 & 1,01 & 1,01 & 1,01 \\
\hline $\begin{array}{l}I_{\mathrm{e}} \\
\text { corrigido }\end{array}$ & 41,4 & 37,2 & 41,5 & 44,4 & 40,4 & 40,4 & 42,4 & 45,5 & 41,4 \\
\hline $\mathrm{fc}(\mathrm{MPa})$ & 41,2 & 38,1 & 41,4 & 49,4 & 40,6 & 40,6 & 43,3 & 50,0 & 41,2 \\
\hline$\Delta \mathrm{fc}$ & $\pm 7,0$ & $\pm 6,5$ & $\pm 7,0$ & $\pm 7,0$ & $\pm 7,0$ & $\pm 7,0$ & $\pm 7,0$ & $\pm 7,5$ & $\pm 7,0$ \\
\hline
\end{tabular}

De acordo com os resultados mostrados no Quadro 2, os valores referentes a MÉDIA I são os resultados das médias dos 16 impactos, em seguida tem-se os valores referentes a 10\% da média para se calcular os limites superior $(>10 \%)$ e inferior $(<10 \%)$. Após obter os valores limites do ensaio, foram descartados os valores que estiveram fora do intervalo representados na tabela pela cor amarelo. Após o descarte de valores, foi feita a média dos valores dentro do limite representados pela linha referente a MÉDIA 
II.

\section{Determinação da profundidade de carbonatação: Solução de fenolftaleína}

Segundo a metodologia do Laboratório Nacional de Engenharia Civil (LNEC), foi escolhido alguns pontos de aplicação da solução. Por se tratar de um elemento químico reagente, foi feito a escolha dos pontos de aplicação em locais de difícil acesso a população por critérios de logística (devido a uma parcela da população ser alérgica ao elemento) e estética (devido a coloração roseada). Os pontos escolhidos foram: Gravidade I (críticos): Base dos pilares 2 e 3 e passeio; Gravidade II (graves): Parte central do pilar 4.

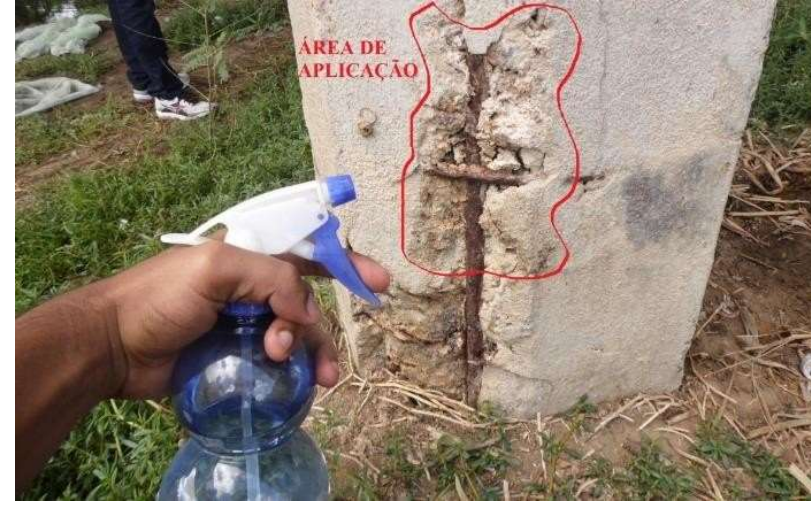

Figura 22: Aplicação da solução de fenolftaleína na base do pilar 2 .

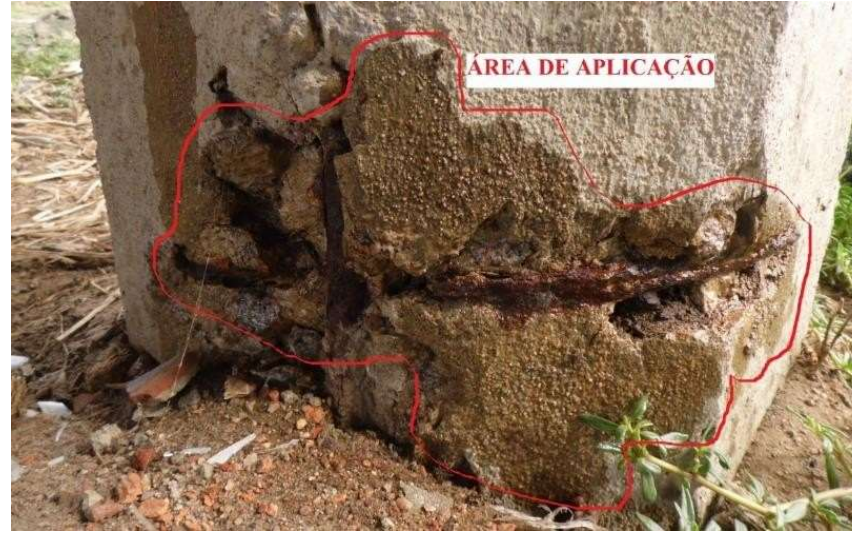

Figura 23: Aplicação da solução de fenolftaleína na base do pilar 3.

As bases dos pilares 2 e 3 apresentaram armaduras expostas que os classificaram em pontos de gravidade I. Ao aplicar a fenolftaleína, como mostra a Figura 22, observa- se que a mesma não reage no concreto, o que indica que toda a área exposta está carbonatada assim como mostra a Figura 23. No passeio foi feito a aplicação da fenolftaleína nas partes de junção entre a ponte e a rodovia, conforme mostra a Figura 24. As junções estavam visualmente desgastadas e ofereciam risco a passagem de pedestres.

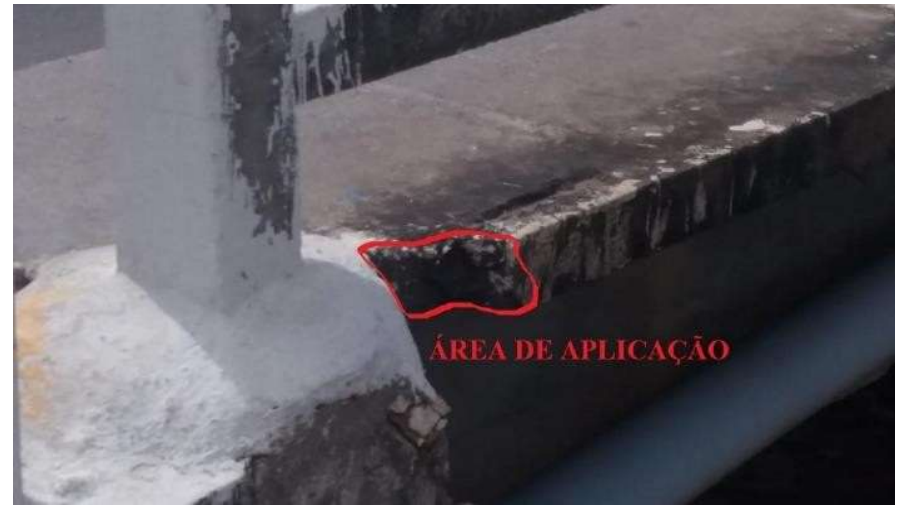

Figura 24: Aplicação da fenolftaleína na junção da ponte.

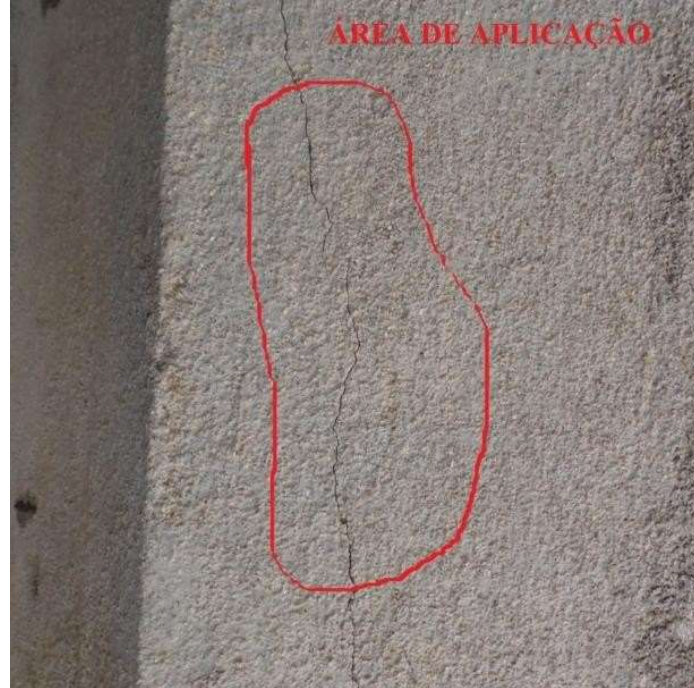

Figura 25: Aplicação da fenolftaleína na parte central do pilar 4.

Ao observar a aplicação solução, o resultado seguiu o mesmo da situação anterior visto que não houve reação do elemento químico logo toda a área superficial de aplicação está oxidada. No pilar 4, como 
citado anteriormente, tem-se uma abertura na parte central do pilar assim foi aplicado a solução de fenolftaleína na extensão da abertura para averiguação do grau de carbonatação, conforme a Figura 25.

Após aplicação da solução, conforme visto na Figura 25, não houve reação, comprovando dessa forma carbonatação superficial. Em todos os lugares de aplicação da solução de fenolftaleína obtiveram como resultado o estado de oxidação superficial, o que pode indicar o quão crítico a estrutura da ponte se encontra.

\section{DISCUSSÃO}

\section{Armaduras expostas}

De acordo com Souza et al. (1998), a provável causa da exposição de armaduras é referente a desagregação do concreto decorrente da oxidação do ferro que no processo, se expande volumetricamente implicando uma pressão confinada suficiente para causar a ruptura do concreto o que pode ser a causa da patologia da Figura 5.

Do ponto de vista de Santos (2015), regiões submetidas ao efeito de tração possui o efeito de carbonatação mais intenso, isso ocorre devido ao esforço de tração provocar aberturas no elemento estrutural e assim resultar na oxidação do aço, o que pode resultar na diminuição da vida útil da estrutura, conforme mostra a Figura 6. De acordo com registros da prefeitura local, em tempos chuvosos o nível do rio Pedra chega próximo ao patamar do passeio. Assim, por falta de revestimento impermeabilizante ou imperfeições construtivas, há a possibilidade da água percolar por entre as aberturas oxidando as armaduras conforme mostra a Figura 7.

De acordo com Damasceno (2018), em seu relatório sobre as águas do rio Pedra cedido pela Secretaria do Meio Ambiente de Delmiro Gouveia/AL, foi observado os valores de ph e oxigênio dissolvido que são índices relacionados a potabilidade e ao estado de conservação das águas. Esse relatório teve o acompanhamento de análises com a duração de 6 semanas conforme mostra o Quadro 3.

Quadro 3: Análise das águas do rio Pedra no ano de 2018.

\begin{tabular}{|c|c|c|c|c|}
\hline Semana & Data & Parâmetro & Medição & Observações \\
\hline \multirow[t]{2}{*}{1} & \multirow[t]{2}{*}{$25 / 07$} & ph & 7.45 & \multirow[t]{2}{*}{ Céu limpo } \\
\hline & & $\mathrm{OD}(\mathrm{mg} / \mathrm{L})$ & - & \\
\hline \multirow[t]{2}{*}{2} & \multirow[t]{2}{*}{$01 / 08$} & $\mathrm{ph}$ & 7.24 & \multirow[t]{2}{*}{ Céu limpo } \\
\hline & & $\mathrm{OD}(\mathrm{mg} / \mathrm{L})$ & - & \\
\hline \multirow[t]{2}{*}{3} & \multirow[t]{2}{*}{$08 / 08$} & $\mathrm{ph}$ & 6.5 & \multirow[t]{2}{*}{ Céu limpo, mas com chuva de madrugada } \\
\hline & & $\mathrm{OD}(\mathrm{mg} / \mathrm{L})$ & 7.41 & \\
\hline \multirow[b]{2}{*}{4} & \multirow[b]{2}{*}{$15 / 08$} & $\mathrm{ph}$ & 7.21 & \multirow[t]{2}{*}{ Céu nublado, mas sem chuva. Ocorrência de chuva na madrugada } \\
\hline & & $\mathrm{OD}(\mathrm{mg} / \mathrm{L})$ & 6.4 & \\
\hline \multirow[t]{2}{*}{5} & \multirow[t]{2}{*}{$22 / 08$} & $\mathrm{ph}$ & 7.21 & \multirow[t]{2}{*}{ Céu limpo e ensolarado } \\
\hline & & $\mathrm{OD}(\mathrm{mg} / \mathrm{L})$ & 1.5 & \\
\hline \multirow[t]{2}{*}{6} & \multirow[t]{2}{*}{$29 / 08$} & $\mathrm{ph}$ & 7.56 & \multirow[t]{2}{*}{ Céu parcialmente nublado e sem chuva. } \\
\hline & & $\mathrm{OD}(\mathrm{mg} / \mathrm{L})$ & 4.6 & \\
\hline
\end{tabular}

Fonte: DAMASCENO (2018).

Damasceno (2018) comenta a parcela de oxigênio dissolvido em águas limpas é geralmente acima de $5 \mathrm{mg} / \mathrm{L}$, em águas ricas de nutrientes normalmente esse valor é superior a $10 \mathrm{mg} / \mathrm{L}$, de acordo com os dados obtidos na semana 5 e 6 o autor comenta que há indícios de águas provenientes de descarte de esgoto além 
da existência e plantas baronesas no local.

Segundo a resolução do CONAMA 357, o teor de ph favorável à vida aquática deve estar entre os níveis 6 a 9. Damasceno (2018) comenta que, de acordo os valores obtidos no Quadro 6, os níveis de ph estão dentro dos padrões estabelecidos pelo CONAMA. Com as informações mencionadas por Damasceno e as evidências das alterações químicas das águas do rio Pedra devido a emissões de efluentes sem tratamento fica evidente de que o elemento responsável da oxidação e exposição das armaduras seja as águas.

\section{Eflorescência}

O sistema de drenagem da ponte visualmente possui imperfeições, visto que na área de passagem dos canos há indícios de infiltração. O sistema por muitas vezes se mostrou ineficaz devido à falta de manutenção, conforme mostra a Figura 16. Conforme mostrado na Figura 16, o sistema de drenagem se mostra irregular visto que se apresenta entupimento por detritos, em ocasiões excepcionais como em chuvas torrenciais pode ser um fator agravante para a utilização da obra.

\section{Esclerometria}

Disposto do valor do fator de correção (k), calculado no Quadro 2, multiplicando pelos valores da MÉDIA II se resulta nos índices esclerométricos corrigidos (Ie corrigido). Com o índice corrigido, foi feito a análise do ábaco do fabricante mostrado na Figura 8 e obtido os valores das resistências (fc) e variações $(\Delta)$ superficiais à compressão (MPa). Em posse dos dados calculados, pode-se primeiramente perceber que o pilar 6 obteve o maior valor em resistência com o valor de $50 \mathrm{MPa}$ em contraste com o pilar 2 que obteve o valor de 38,1 MPa o que, em comparação, o pilar 2 apresentou uma redução de resistência de $23,8 \%$ ao pilar 6.

Também foi possível perceber que os valores das faces opostas do pilar 4 obtiveram o mesmo valor de resistência, em contraponto os valores das faces opostas do pilar 3 obtiveram uma diferença de aproximadamente $16,19 \%$ de redução entre as duas faces, que pode ser resultante na desagregação e carbonatação do concreto devido à ação da água no local. Segundo a norma NBR 7584 (2012), a ação da carbonatação nos elementos estruturais pode superestimar o valor da resistência em até $50 \%$ dos valores devido à superfície degradada, dessa maneira faz-se necessária a extração de corpos de prova dos elementos estruturais para um maior aprofundamento e certeza do estado atual da peça estrutural.

\section{CONCLUSÕES}

Por meio do presente trabalho, foi possível fazer uma análise das manifestações patológicas presentes na ponte sobre o rio Pedra, localizada no município de Delmiro Gouveia/AL, de cunho quantitativo e qualitativo, onde foi constatado que o elemento principal destas é a água, aliada à falta de manutenção corretiva e preventiva periódica torna-se um risco para os usuários. As falhas mais encontradas foram: armaduras expostas, eflorescência, desgaste das juntas de dilatação, infiltração, entupimento do sistema de drenagem, desnivelamento, desagregação do concreto, aberturas em diferentes tamanhos, furos e 
irregularidades com as normas vigentes.

Por meio das análises visuais e dos ensaios feitos, pode-se afirmar que o desempenho estrutural atual da obra compreende um estado preocupante que necessita de atenção e providência das instâncias públicas, visto a importância econômica que a via proporciona ao município além da obrigatoriedade de se preservar o patrimônio público. Por fim, a despeito das limitações dos ensaios, é possível concluir que a ponte estudada deve, impreterivelmente, passar por um processo fundamental de manutenção e revitalização estrutural.

\section{REFERÊNCIAS}

ABNT. Associação Brasileira de Normas Técnicas. NBR 6118: Projeto de estruturas de concreto. 3 ed. Procedimento. Rio de Janeiro: ABNT, 2014.

ABNT. Associação Brasileira de Normas Técnicas. NBR 7584: Concreto Endurecido: Avaliação da dureza superficial pelo esclerômetro de reflexão: Método de ensaio. 2 ed. Rio de Janeiro: ABNT, 2012.

ABNT. Associação Brasileira de Normas Técnicas. NBR 9452: Inspeção de pontes, viadutos e passarelas de concreto. 4 ed. Rio de Janeiro: ABNT, 2019.

ABNT: Associação Brasileira de Normas Técnicas. NBR 14718: Guarda-corpos para edificação. Especificações. Rio de Janeiro: ABNT, 2001.

ABNT. Associação Brasileira de Normas Técnicas. NNBR 15575: Edificações Habitacionais: Desempenho. Rio de Janeiro: ABNT, 2013.

DAMASCENO, L. M.. Relatório de Estágio Curricular em Engenharia Civil. Delmiro Gouveia: Secretaria Municipal do Meio Ambiente, 2018.

DNIT. Departamento Nacional de Infraestrutura e Transportes. Manual de inspeção de pontes rodoviárias. Instituto de Pesquisas Rodoviárias - IPR 709. 2 ed. Rio de Janeiro: DNIT, 2004.

DNIT. Departamento Nacional de Infraestrutura e Transportes. Norma 122/2009: Ponte e viadutos rodoviários: Estruturas de concreto armado- Especificação de serviço.
Instituto de Pesquisas Rodoviárias - IPR. Rio de Janeiro: DNIT, 2009.

DOREA, S. C. L.; SANTOS, D. G.; SALES, A. T. C.; SILVEIRA, P. M. D.. Avaliação patológica da estrutura de concreto armado e dos componentes de uma edificação construída em 1914. Scientia Plena, v.6, n.12, 2010.

IBAPE. Instituto Pernambucano de Avaliações e Perícias de Engenharia. Fundamentos da patologia das estruturas nas pericias de engenharia. Departamento de Engenharia Civil, 2003.

LNEC. Laboratório Nacional de Engenharia Civil. E391: Determinação da profundidade de carbonatação de betões, argamassas ou outros materiais cimentícios: Método de ensaio. Procedimento. 2019.

ROQUE, J. A.; MORENO JUNIOR, A. L.. Considerações Sobre a Vida Útil do Concreto. In: ENCONTRO NACIONAL DE PESQUISA-PROJETO-PRODUÇÃO EM CONCRETO PRÉMOLDADO, 1. Anais. São Carlos, 2005. p.11.

SANTOS, A. V. B.. Corrosão de armadura em estruturas de concreto armado devido a carbonatação. Revista Especialize On-line IPOG, Goiânia, v.1, n.10, p.21, 2015.

SOUZA, V. C; RIPPER, T.. Patologia, recuperação e reforço de estruturas de concreto. São Paulo: Pini, 1998.

THOMAZ, E. C. S.. Esclerômetro. Notas de aula: Procedimento. Instituto Militar de Engenharia, 2007.

A CBPC - Companhia Brasileira de Produção Científica (CNPJ: 11.221.422/0001-03) detém os direitos materiais desta publicação. Os direitos referem-se à publicação do trabalho em qualquer parte do mundo, incluindo os direitos às renovações, expansões e disseminações da contribuição, bem como outros direitos subsidiários. Todos os trabalhos publicados eletronicamente poderão posteriormente ser publicados em coletâneas impressas sob coordenação da Cognitionis Publishing, da Companhia Brasileira de Produção Científica e seus parceiros autorizados. Os (as) autores (as) preservam os direitos autorais, mas não têm permissão para a publicação da contribuição em outro meio, impresso ou digital, em português ou em tradução. 